\title{
Pais Encarcerados: Filhos Invisíveis
}

Convicted parents: Invisible children

Andréa Marília

Vieira Santos

Pontifícia

Universidade

Católica de

Minas Gerais

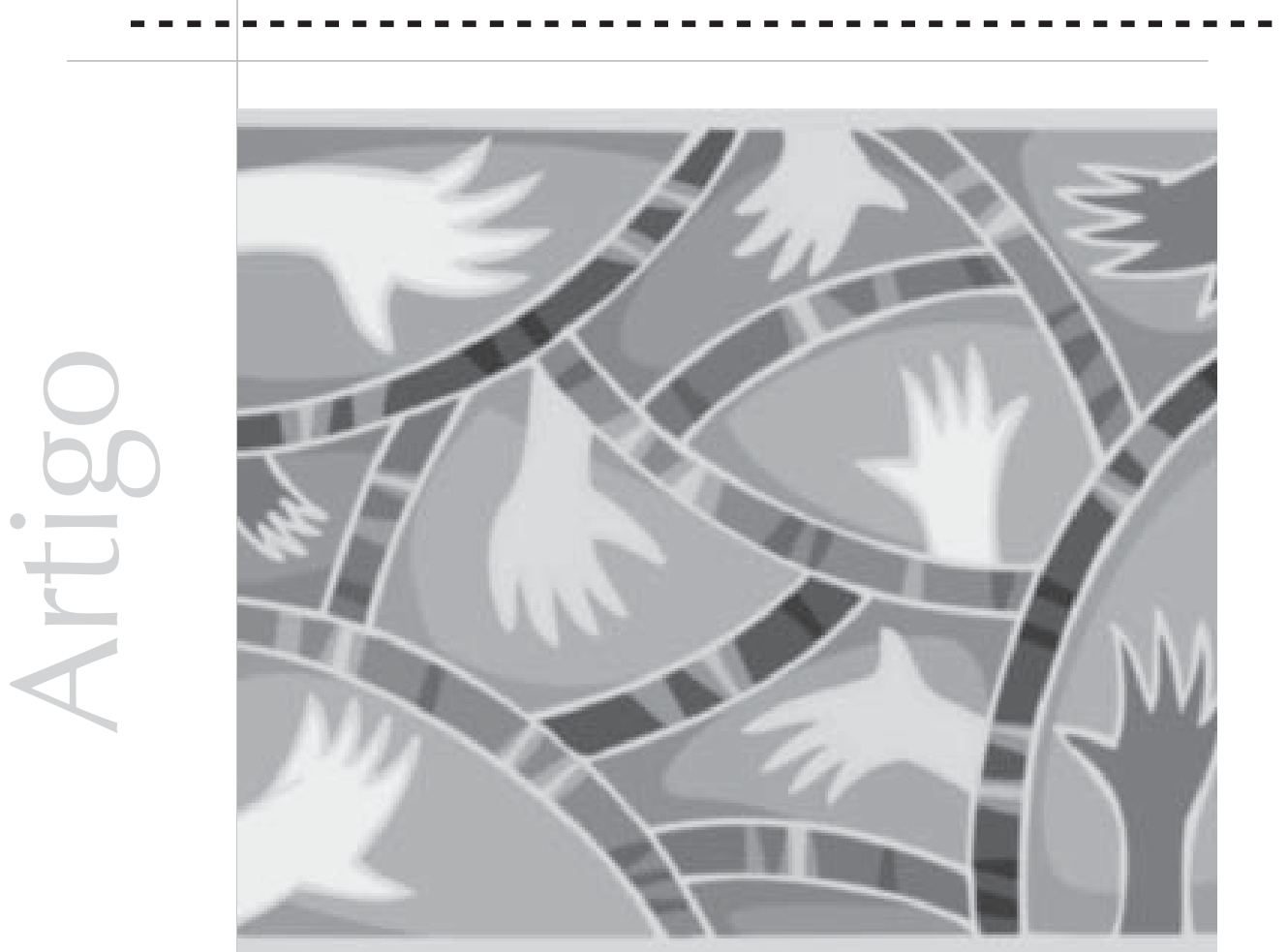




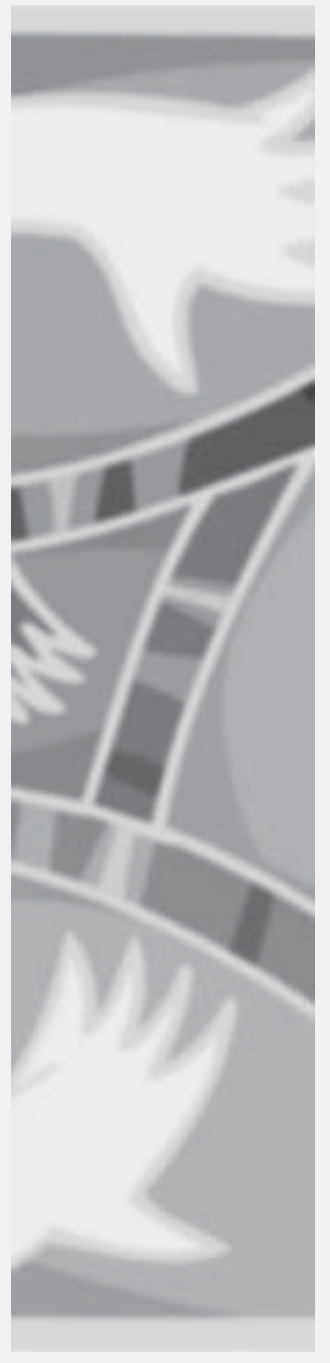

Resumo: Esta pesquisa visa a fomentar uma discussão que consideramos de grande relevância social. Como estudantes de Psicologia, curiosos a respeito do comportamento humano e das relações sociais, uma questão chama nossa atenção: como uma criança pequena vive a experiência da referência paterna submetida à tutela do Estado? Embora representem enormes avanços, na prática, a Lei de Execução Penal e O Estatuto da Criança e do Adolescente parecem inconciliáveis: o direito ao convívio e o vínculo da criança com o pai tutelado pelo sistema carcerário apresentase, de fato, barrado. As regras de condutas igualam o tratamento dispensado a adultos e crianças. Diz uma criança de quatro anos: "... a gente abaixa e levanta três vezes, é igual fazer xixi." Torna-se indispensável rever os procedimentos adotados; o que ocorre pode, no mínimo, ser tomado como maus-tratos.

Palavras-chave: crianças, cárcere, pais, cidadania.

\begin{abstract}
This research aims to stimulate a discussion that we consider of great social relevance. As students of Psychology, curious about the human behavior and the social relations, a question calls our attention: how does a small child go through the experience of the submitted paternal reference to the guardianship of the State? Although they represent enormous advances, in daily life, the Law of Criminal Execution and the Statute of the Child and the Adolescent seem irreconcilable: the right to conviviality and the bond of the child with the convicted are, in fact, barred. The rules of behaviors equal the treatment given to adults and children. A child of four years old says: "...we crouch and raise three times. It is equal to pee". It is essential to review the adopted procedures; what happens can, at least, be taken as bad-treatment.
\end{abstract}

Key words: children, jail, parents, citizenship.

Esta pesquisa visa a fomentar uma discussão que consideramos de grande relevância social. Como estudantes de Psicologia, curiosos a respeito do comportamento humano e das relações sociais, uma questão chama nossa atenção: como uma criança pequena vive a experiência da referência paterna submetida à tutela do Estado?

Nunca estivemos tão amparados pelo Direito; no entanto, sabemos que, de fato, regras e comportamentos, em geral, muito se distanciam da legalidade. E é nessa brecha que trabalharemos. A despeito da existência da Lei de Execuções Penais - LEP, é notório o despreparo, a desinformação e a ausência de estruturas que dificultam ou impedem a sua aplicação. À luz do art. 41, Seção II, da LEP, que versa sobre os direitos do preso condenado ou provisório e trata do direito das visitas, refletimos sobre como é instigante o fato de que sua elaboração não determine, enumere ou discrimine as relações sociais que poderão ser estabelecidas com um preso durante a visita. Quanto à visita de crianças, então, provavelmente por um descuido do legislador, possibilitou-se às instituições carcerárias o uso do poder discricionário, ou seja, cada instituição 
tem seu regimento interno no que diz respeito a essas visitas.

Contudo, não se pode deixar de anunciar os avanços ocorridos no que diz respeito aos tratamentos dispensados aos presos. É interessante observar que o respeito à dignidade humana já acenava para uma inevitável mudança das políticas públicas carcerárias, conforme Thompson (1993) trata em seu livro A Questão Penitenciária.

A Constituição de 1988 traz uma nova feição para o Código Penal; no entanto, as mudanças ocorreram gradativamente, a partir da publicação das Leis de Execuções Penais, no que se refere aos presos provisórios e sentenciados, que regularam e normatizaram o tratamento dispensado a estes. Como o Direito é posterior ao conflito, não é de se estranhar a ausência da criança na referida legislação.

Considerando algum parentesco com o presidiário, podemos inferir que a ausência de referência às visitas, na Lei, implica uma invisibilidade da criança enquanto sujeito de direitos. Compreender como a criança vivencia essa relação de poucos contatos, da qual pouco se fala, mas muito se sente, será nosso desafio.

Nossa intenção, com esta pesquisa, é entender como é, para a criança, a experiência de ter um pai encarcerado e conviver em um ambiente onde os familiares se manifestam penalizados com tal situação. Sendo membro desse grupo de pesquisa e tendo carreira policial, pude perceber a dificuldade de as crianças serem ouvidas a respeito dessas questões, tanto nas famílias quanto no sistema carcerário.

O que percebemos quanto aos vínculos possíveis - e quase impossíveis - das crianças com seus pais encarcerados nos leva a questionar a postura do Estado, de indiferença, e que reflete as relações humanas estabelecidas na sociedade, na qual, para os encarcerados, o que se perde é a liberdade. Já para a infância, resta a difícil condição de não conviver cotidianamente com os pais e, posteriormente, quem sabe, tentar restabelecer esses vínculos.

A nós, cidadãos e estudantes, cabe, nesse momento, frente à degradante condição experimentada pelas crianças, a opção de pesquisar para saber como representam e elaboram os vínculos com os pais encarcerados.

\section{Um pouco sobre a população carcerária brasileira}

Traçar o perfil da população carcerária faz-se necessário, uma vez ser notório que a violência e a criminalidade estão cada vez mais associados a questões sociais. Existem diversas vertentes que estudam e justificam a existência da criminalidade. Falar em segurança pública costuma ser garantia de reeleição.

Dessa forma, ocorre atualmente uma supervalorização de todo mecanismo de segurança, focando não a causa da violência, mas, sobretudo, o que se deve fazer com seus efeitos. Programas de aconselhamento são criados e parcerias estabelecidas, como, por exemplo, o policiamento comunitário. Como em um mercado, podemos escolher, conforme pudermos pagar, o tipo e nível de segurança a ter acesso.

O discurso do Estado é paternalista: a grande preocupação é proteger o cidadão do "bem", é legitimar o discurso desse que tem o direito de nada fazer e de ser protegido. Delega-se então ao Estado, como ao pai, o papel de protetor e guardião.

Mas proteger-nos do quê? Do nosso semelhante. O termo "semelhante" nos incomoda, pois implica colocarmo-nos no lugar 
de alguém que não possui uma representação na sociedade. Parece ser mais fácil ignorar sua existência, demarcar seu lugar de pouca valia, construindo mais presídios, ou o que está ao nosso alcance, como subir o vidro do carro. Afinal de contas, quem são essas pessoas que despertam o nosso medo?

As penitenciárias nunca tiveram tantos encarcerados, e os dados divulgados pelo Departamento Penitenciário Nacional - DEPEN revelam que, em dezembro de 2004, havia nelas uma população de 336.358 pessoas. O acesso à informação nunca foi tão amplo, porém, podemos refletir que os encarcerados têm sido condenados também pela mídia elitista e preconceituosa, que nos leva a questionar se muitas das pretensões de cidadania e de consumo obtidas pela prática do ilícito não se dariam pela necessidade de os infratores se reconhecerem noutras "personagens", veiculadas nas mesmas mídias, pelo desejo de se fazerem, de certa forma, semelhantes a elas. É uma hipótese, da qual essa alta criminalidade é um registro, ou, quem sabe, a maneira encontrada pelos sujeitos de se fazerem notar. Seria um grito de socorro, a necessidade de um encontro com a lei. Nesse contexto, o sujeito atua o tempo todo. O apelo à lei é escancarado.

Ao propor ouvir familiares de presidiários e, em especial, as crianças, identificamos, em suas histórias, a presença de um núcleo tradicional, reconhecendo as figuras maternas e paternas. Percebemos, entretanto, que essas relações se encontram profundamente marcadas pelas práticas criminais dos genitores. Desenvolver um pensamento lógico em torno do enfrentamento da experiência da criança filha de pais encarcerados, de modo a humanizá-la, pouco ainda se faz possível na prática, na qual a pena está intimamente ligada à vingança, conforme trata Foucault em Vigiar e Punir (2003). Isso implica dizer que o discurso de ressocialização, de momentos de reflexão em torno de experiências isoladas, faz-se possível na busca dos modelos positivos que possamos fazer manter, como, por exemplo, a do modelo prisional da Associação de Proteção e Assistência aos Condenados APAC, que, apesar de sua existência, ainda não faz parte do imaginário da sociedade.

A grande parte da população carcerária mantém-se esquecida pelos governantes, que continuam tratando dos efeitos da criminalidade e desconsideram, dessa forma, suas origens. Cemitérios de mortos vivos são o que significam os centros carcerários, locais onde pessoas não diferentes de nós ocupam certo lugar demarcado pela sociedade. Nesse local, além de perdas físicas e emocionais, sujeitos à mercê da vontade e da perversão de outros, nem sempre qualificados para as funções, têm imputada sobre si mesmos ainda a difícil missão de se recuperarem.

\section{Estado e infância}

A criança tem seus direitos sociais definidos pela Constituição Federal, pelo Estatuto da Criança e do Adolescente e pela Lei de Diretrizes e Bases da Educação Nacional, dentre outras regulamentações decorrentes da Carta Maior. Segundo esses documentos, a criança tem direito a ser criada no seio da família, seja ela a natural, preferencialmente, ou a substituta, em casos especiais e, ainda, pelo Estado, de forma suplementar. Tem direito à educação voltada para suas necessidades e características e às atividades culturais. A legislação define que a criança e o adolescente também não podem trabalhar, salvo como aprendizes, assegurando que tenham tempo para desenvolver-se o melhor possível. Boa parte da atenção desses textos legais é voltada para a criança, a fim de que ela tenha melhores condições de ter acesso às atividades recomendadas para a sua idade. A esse respeito, a Constituição Federal evidencia o princípio de igualdade, nas dimensões estática e dinâmica: o art. 5o da Constituição acolhe o sentido estático: "todos são iguais perante a lei, sem distinção de
A grande parte da população carcerária mantém-se esquecida pelos governantes, que continuam tratando dos efeitos da criminalidade e desconsideram dessa forma, suas origens. Cemitérios de mortos vivos

são o que significam os centros carcerários, locais onde pessoas não diferentes de nós ocupam certo lugar demarcado pela sociedade. 
A revista não é nem pode ser considerada uma simples operação de controle: ela agride, ao mesmo tempo, o corpo real, o corpo imaginário e o corpo simbólico. 0 homem revistado é um homem possuído

Buffard, apud Thompson qualquer natureza." O art. 3º, inciso III, prevê, em sua segunda parte, o sentido dinâmico, pois fixa, como objetivo do País, a redução "das desigualdades sociais e regionais", como relatado em documento de 2002, do Movimento de Interfóruns de Educação Infantil do Brasil.

O Estatuto da Criança e do Adolescente (Lei no 8.069/90) define uma política mais descentrada de atendimento à criança, baseada no princípio da democracia participativa, com a criação de conselhos, dos quais participam órgãos públicos e organizações não-governamentais. Não existe uma legislação específica que remeta às necessidades e formas de acolhimento e atenção às crianças que têm seus pais encarcerados. Dessa forma, o tratamento dispensado a essas, no momento em que visitam um progenitor em um centro carcerário, não difere daquele dispensado ao adulto, violência impossível de se traduzir, como escreveu Buffard, citada por Thompson: A revista não é nem pode ser considerada uma simples operação de controle: ela agride, ao mesmo tempo, o corpo real, o corpo imaginário e o corpo simbólico. O homem revistado é um homem possuído (Buffard, apud Thompson, 1998, p.63).

Várias críticas são cabíveis frente à postura do Estado no caso da visita da criança, e uma delas refere-se a tal tratamento. É justo que a criança, sujeito de desejo, sujeito em desenvolvimento, tenha sua infância marcada pela ausência de políticas que atendam direta e indiretamente quem está sob a tutela do Estado? Levando-se em consideração a população carcerária, podemos multiplicar por duas ou três crianças o número daquelas que compõem cada núcleo familiar com a presença do presidiário. Será esse número pouco significativo para representar um país daqui a quinze ou vinte anos? Como o Estado pode viabilizar mudanças nesse sentido, recebendo-as como sujeitos de direitos? Essas são questões de primeira importância acerca da produção de uma infância que tenha, de fato, seus direitos respeitados no Brasil.

\section{Ouvindo mães e crianças filhas de pais encarcerados}

Neste capítulo, apresentamos as vozes das crianças e de suas mães sobre a experiência de submissão às regras impostas pelo Estado, por ocasião de visitas a centros carcerários. Destacamos e refletimos, a seguir, alguns cortes significativos que identificamos nas escutas e nas três entrevistas feitas, depois de abordar mães e crianças numa fila de visita a um presídio e solicitar um encontro para discutir o assunto em suas casas.

Identificamos as entrevistas como E1, a de uma criança de 4 anos, sexo feminino; E2, a de uma criança de 2 anos, sexo masculino, e E3, e conversamos com suas crianças e suas mães. Fica clara a trajetória de vida de cada família após a prisão do pai. Percebemos, nos relatos, as relações dessas crianças com os pais, geralmente manifestadas de forma saudosista:

"Tudo para ele é o pai. Ele chora muito." (Mãe)E2.

"Qualquer foto, pra colocar no porta-retrato, tem que ter os dois, senão, nada feito. Teve uma época que ele até dormia com essa foto." (Mãe)E2.

"Você tem foto dele?" "Sim."E3.

"Você sente saudades de seu pai?" "Sim."E3.

"O que você gostava de fazer com seu pai?" "Bicicleta." E3.

"Ele já deixou eu dirigir o carro dele."E1.

\section{Presença do pai}

Apesar da ausência física em casa, o pai sempre é presente em lembranças assim como em 
fotos, sendo o dia de visita, apesar de todos os entraves, um momento propício para matar a saudade e fortalecer os vínculos estabelecidos.

"Ele ganhou esse celular, e sempre brinca que está falando com o pai." (Mãe) E2.

"Às vezes o pai dele liga, o G. fica muito feliz, e, assim que chego em casa, ele me conta..." E2.

Novamente G. traz outro objeto consigo, dessa vez uma mochila, que faz questão de nos mostrar. "Ele é dado para estudar, é doido pra ir pra escolinha..."

Quando ele ganhou esta mochila, a mãe nos diz que houve um grande desejo da criança de mostrá-la ao pai, mas os mecanismos de segurança não permitiram.

\section{Pena solidária}

Como ponto coincidente, percebemos que toda dinâmica familiar é alterada, e passa a fluir tendo, como ponto central, o genitor encarcerado. De obrigações assumidas até constrangimentos morais, passam a fazer parte de um período que todos esperam terminar com a saída do cônjuge da prisão.

Podemos dizer que o período de cumprimento da pena será marcado pela entrada de todos os familiares no mundo do cárcere.

A mãe de R2 informa que o pai foi preso há dez anos, o que implicou alterações na rotina de toda a família. Moravam com a família, a avó paterna, e G. diz: "Quis ficar lá por causa do G. (criança), mas nós não combinamos. Além do mais, casa de mãe é melhor."R2.

O pai é bastante presente na dinâmica de vida estabelecida por essa mãe, que fala do pequeno apoio recebido dos familiares de seu marido para ajudar na manutenção do filho e do próprio esposo na prisão: "Eles dão trinta reais por mês. Não dá pra nada."
A colocação dessa mãe mostra-nos como a pena implica não só o adulto que cometeu o ilícito; todas as pessoas, ligadas ao preso ou à família deste, contribuem ou participam de alguma maneira a fim de permanecerem em contato com o detento.

Relato da avó de E3: "Deus vai ajudá e tem o advogado, né? Tá difícil, mas a gente tá pagando como pode."

"E aí meu pai fica lá um tempão, esperando o dia da visita, ele só toma banho no dia da visita, não toma banho todo dia." E1.

"Só pode tomar banho no dia da visita? Ele que te contou?" "Porque a água lá é muito fria." E1.

"Aí você leva biscoito, miojo..." R: "Tem que agachar duas vezes. Duas vezes tem que agachar." E1.

"Para o moço ou para a moça?" "Para a moça." E1.

"Toda vez é assim?" R: "Elas ficam olhando e depois tem que fazer fila para entrar." E1.

"E você liga de ter que tirar a roupa?" "É ruim. Parece que vai fazer xixi." E1.

\section{Momentos que antecedem a visita}

Sem dúvida, o momento da revista é apontado pelas mães como o mais angustiante. "Agora G. começa a entender... ele gruda em mim e chora muito..." R2. "Os agentes não têm paciência, e logo acham que estamos escondendo alguma coisa."

Essa mãe continua seu relato alterando um pouco o tom de voz: "Eles usam aquelas luvas, olham com um "olhar" ruim para as crianças. Não tem uma que não fica nervosa. Eu não sei como, mas deveria existir outra maneira da revista acontecer."
"Ele ganhou esse celular, e sempre brinca que está falando com o pai." (Mãe) E2. 
"O moço que fala: 'tem que separar'. Aína hora de entrar tem que ter fila." $E 1$.
"Você chega caladinha e já vai falar com seu pai?"

"O moço que fala: ' tem que separar'. Aí na hora de entrar tem que ter fila." E1.

"Você vai de manhã?" "Cedo. E eu fico com sono e com minha barriga doendo." E1.

"E porque a barriga dói?" "Porque eu fico toda bamba."E1.

"Seu pé dói, sua barriga dói... O que acontece? Dói na hora que você chega lá ou dói quando você está indo?" "Lá dentro pára."E1.

"Aí quando você chega lá, conversa com quem?" "Converso com o papai."E1.

"Ele já fica esperando lá na porta?" "Não. Lá dentro. Cá dentro que ele fica para visitar." E1.

\section{O encontro com o pai}

Passar por situações tão constrangedoras tem levado as crianças a um comportamento inesperado para os pais. Elas dormem no momento do encontro. Apesar de ser tão esperado, o desgaste psíquico a que são expostas, aliado à falta de diálogo, traduz o comportamento de sonolência como uma forma de preservação do organismo.

"Você fala com seu pai que fica com saudade dele?" "Só fico com saudade quando eu falo no telefone e quando penso nele. Aí eu fico com vontade de chorar. Mas não choro!" E1.

"E porque você não chora?" "Porque todo mundo me xinga e me bate. Ai eu fico com vergonha." E1.

"Mas todo mundo chora, E1, não precisa ter vergonha..."

\section{Considerações finais}

A despeito da dificuldade em encontrar elaborações teóricas sobre a problemática de crianças que vivem a experiência de pais encarcerados para subsidiar esta pesquisa, esse empecilho não foi suficiente para impedir a conclusão do estudo.

As questões trazidas através das entrevistas mostraram-nos que poderíamos fazer o caminho inverso. Antes de falarmos apoiados em estudos sobre as necessidades e deficiências que envolvem as crianças que, de certa forma, se relacionam com o sistema carcerário, tornou-se fundamental que primeiro soubéssemos de quem estávamos falando.

O que é ser uma criança? O avanço trazido pelo Estatuto da Criança e do Adolescente de fato aproxima o discurso jurídico da realidade vivida pelas crianças?

Nossa pesquisa revela que não. Descobrimos que caminhamos sob fogo cruzado, em um terreno desconhecido. As vertentes legais do Estatuto da Criança e do Adolescente e da Lei de Execuções Penais estão na mesma escala de importância e valor para a criança e o presidiário, entretanto, parecem inconciliáveis frente ao que experienciam os sujeitos, como num impasse: de um lado, o direito do presidiário ao contato com seus familiares; de outro, a proteção à criança, prevista no Estatuto da Criança e do Adolescente.

As duas legislações representam um grande avanço ao dignificar, humanizar e respeitar a individualidade e a singularidade humanas. No entanto, percebe-se que a adequação do Estatuto da Criança e do Adolescente para tratar da interação com um pai tutelado pelo sistema carcerário se faz de maneira precária; verificase, de fato, a invisibilidade da criança e de seus direitos.

Se, de certa forma, se age dentro dos preceitos legais assegurados às crianças no que tange ao convívio com seus familiares, por outro lado, a aplicação da Lei de Execução Penal, que garante ao preso o direito à visita dos familiares, atende apenas aos requisitos básicos de 
segurança para impedir fuga ou motim. Com isso, mostra como essa Lei ignora o direito ao convívio desses adultos com seus filhos crianças.

Percebemos a preocupação exacerbada com o grupo de visitantes organizados em fila. Estabelece-se um jogo entre culpados e inocentes, onde quem sai perdendo é a criança. Há uma distância entre os visitantes e os agentes de segurança no modo como estes tratam aqueles, quase como se tivessem também cometido delitos; observamos esse fato em certas condutas de indiferença e nos modos de tratamento rudes que presenciamos, nos poucos momentos em que acompanhamos as mães com as crianças na fila. A imposição de regras e condutas adotadas dentro dos centros carcerários nos momentos que antecedem as visitas igualam o tratamento dispensado a adultos e crianças, como mostra o relato de uma criança de quatro anos: “... a gente abaixa e levanta três vezes, é igual fazer xixi..."

Ao dispensar às crianças o tratamento dirigido aos adultos, desconsideram-se os direitos fundamentais das crianças de serem tratadas com dignidade e respeito, de serem reconhecidas em sua condição cidadã. Tornase indispensável rever os procedimentos adotados para atender as crianças nas visitas aos pais. Podemos pensar que se trata, ao menos, de maus-tratos às crianças, de acordo com o ECA.

A imputabilidade da pena não se relaciona apenas com o preso, mas toda a família é penalizada, e, longe de acreditar estar dentro da normalidade, aquilo que é imposto àquele que transgride a lei é quase estendido aos familiares, e, percebemos, fortemente sentido pelas crianças. Neste momento, tentaremos falar apenas pelas crianças.

Não que as crianças não se expressem, mas estão subjugadas ao desejo do outro, presas a conflitos que, muitas vezes, fogem aos próprios anseios. É importante ressaltar que, para a criança, o único desejo é encontrar o pai, pouco importando em qual situação, percebemos pelas entrevistas. Como estudantes de Psicologia, entendemos essa suposta inabilidade das crianças em expressarse e constatamos que as crianças falam, sim, precisam é ser escutadas. Por exemplo, quando, no relato de R1, a criança diz: "... choro à noite, depois da visita, mas a minha mãe não gosta..."

Os riquíssimos relatos mostram-nos que, apesar da pouca idade, mas inseridas no mundo da linguagem, as crianças têm capacidade e condição, dentro de seu entendimento, de compreender as situações a que são expostas e manifestam, assim, seu descontentamento através do choro, da birra, da indiferença, da agressividade, e da agitação, por exemplo (Dolto, 1999).

Descobrimos como a sabedoria infantil não se resigna diante das injustiças e da violência, mesmo com o limitado aparato verbal. Comportamental e socialmente, manifestam a própria dor e ansiedade, acirradas no procedimento da visita, através de sintomas e sinais como dor de barriga, dor de cabeça e sonolência, que são tratadas com indiferença pelos profissionais e até por boa parte dos familiares. Percebemos a importância da figura paterna e a presença dessa ausência para as crianças, viável através da figura materna e do núcleo familiar, assim como nas atitudes desenvolvidas pelas crianças no sentido de participarem ativamente dos preparos para o dia da visita. Os relatos das mães mostramnos o quão especial é esse dia, o que foi percebido pela rotina estabelecida naquele dia e pelos comportamentos apresentados pelas crianças, com um alto desgaste psíquico. A alta ansiedade, seguida de euforia e de sono profundo, evidenciam como é angustiante, para a criança, vivenciar tal situação, e, como 
não é escutada, ela chora, tem dor de barriga, dor de cabeça, consegue fazer com que falem com ela e por ela e a coloquem no colo, esperando, muitas vezes, que o silêncio as console.

Ouvindo esse silêncio, acreditamos ser possível tornarmo-nos multiplicadores de nossa experiência, visando ao bem-estar infantil. Percebemos que é necessário que orientações acerca de condutas prévias e durante a visita da criança sejam formalizadas e repassadas aos familiares e aos agentes de segurança pública, afirmando os direitos e as necessidades das crianças, servindo como referência na prática dos direitos humanos e, particularmente, humanizando o tratamento dispensado às crianças filhas de pais encarcerados.
Parece soar contraditório e ousado relacionarmos segurança pública a direitos humanos, principalmente ao sabermos sobre os anos de chumbo que envergonharam e assombraram a história de nosso país. Felizmente esse discurso se encontra ultrapassado, basta observar a preocupação com que os novos agentes de segurança pública são formados e aperfeiçoados, tendo incluídos, nos currículos das academias, temas relacionados aos direitos humanos e à cidadania.

A pretensão deste trabalho não se limitou a apontar os problemas; quem sabe possamos começar a acertar algumas arestas da desigualdade, da indiferença e do descaso com a ajuda da Psicologia, amenizando conflitos subjetivos e coletivos com base nos direitos humanos. 
Andréa Marília Vieira Santos Graduanda do 6 o período de Psicologia PUC Coração Eucarístico - BH- Rua Opala, 372, Bairro São Joaquim Contagem - MGCEP 32113100 (031) 3379512987445554

E-mail:andreavieirabh@hotmail.com

BRASIL. Constituição de 1988: texto constitucional de 05 de outubro de 1988, com alterações adotadas pelas emendas constitucionais de revisão no 1 ao no 6/94. Brasília: Senado Federal, 1994.

BRASIL. Estatuto da Criança e do Adolescente: convenção sobre os direitos da criança. Brasília: UNICEF, 2002.

BRASIL. Ministério da Saúde. Interfóruns de Educação Infantil do Brasil - Educação Infantil: Construindo o Presente. Campo Grande: UFMS, 2002.
DOLTO, Françoise. As Etapas Decisivas da Infância.São Paulo: Martins Fontes, 1999.

FOUCAULT, Michel H. Vigiar e Punir.Rio de Janeiro: Jorge Zahar, 1991.

MIRABETE, Júlio Fabrini. Execução Penal: Comentários à Lei no 7210, de 11-7-84. São Paulo: Atlas, 1997.

THOMPSON, Augusto. A Questão Penitenciária de Acordo com a Constituição de 1988. Rio de Janeiro: Forense, 1988.
Referências 